ARTIGO

Recebido em: 28/04/2017

Aceito em: 09/04/2018

\title{
Gestão do conhecimento e inovação em startups Catarinenses
}

\author{
Knowledge management and innovation in Santa Catarina startups
}

\author{
Mariana Pereira da SILVA (mariiana.pereira@gmail.com)* \\ Larissa Lara GABIATTI (larissagabiatti@hotmail.com)** \\ Marcelo MACEDO (marcelomacedo@egc.ufsc.br)* \\ Nina Rosa Cruz GERGES (ninarcg@gmail.com)*** \\ * Departamento de Engenharia e Gestão do Conhecimento - UFSC. \\ ** Arquivista - UFSC. \\ *** Doutoranda na Engenharia e Gestão do Conhecimento - UFSC.
}

\section{Resumo}

O objetivo deste artigo é identificar os conhecimentos críticos voltados para o incremento do processo de inovação em startups catarinenses. 0 procedimento metodológico adotado é um estudo de casos múltiplos. Os resultados mostram que nem todos os conhecimentos estudados nas empresas podem ser considerados como críticos para o incremento da inovação. Ainda foi possível constatar que nem sempre a prática organizacional está de acordo com a literatura.

Palavras-chave: Inovação. Startup. Gestão do Conhecimento. Conhecimento Crítico.

\section{Abstract}

The objective of this article is to identify critical knowledge aimed at increasing the innovation process in Santa Catarina startups. The methodological procedure adopted is a multiple case study. The results show that not all the knowledge studied in companies can be considered as critical for the increment of innovation. It was still possible to verify that organizational practice is not always in accordance with the literature.

Keywords: Innovation. Startup. Knowledge Management. Critical Knowledge.

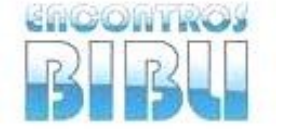

\section{INTRODUÇÃO}

Os países, desde o início do processo de globalização, têm como principal característica a competitividade econômica. Lastres e Albagli (1999) caracterizam a globalização como a formação de um mundo sem fronteira em qualquer mercado, o que formaria, em sua visão, setores incontroláveis. A eficiência de países se baseia, portanto, na competitividade de suas empresas, na eficiência do conjunto de estruturas produtivas, na qualidade da infraestrutura tecnológica e na inter-relação entre as partes do sistema de produção.

Nesse contexto, as empresas do ramo tecnológico vêm aos poucos dominando vários setores de mercado, pois, como Muniz (2000) ressalta, a inserção da tecnologia é uma maneira da empresa ou país adquirir vantagens comparativas competitivas, principalmente se essa for uma nova base tecnológica, do domínio predominante da empresa em questão.

v. 23, n. esp., 2018 p. $126-142$

ISSN 1518-2924

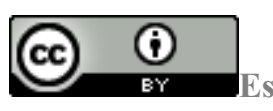

Esta obra está licenciada sob uma Licença Creative Commons. 
O setor tecnológico é inconstante, está em progressivas mudanças, como levanta Zucoloto (2004). Se uma empresa está desenvolvendo um novo produto ou processo, não existe garantia que assegure que outros estejam formulando trabalhos similares ou melhores. 0 fato do setor necessitar de constantes inovações e renovações leva o mercado a buscar meios de incentivar, não só grandes empresas, mas as pequenas ideias que podem revolucionar o mercado. 0 setor tecnológico é o principal utilizador de novo modelo de negócio de startups, por ser um campo muito inovador e com tendências de crescimento rápido.

Diante disso, o objetivo deste trabalho é identificar os conhecimentos críticos voltados para o incremento do processo de inovação em startups catarinenses.

0 artigo está estruturado da seguinte forma: primeiramente são apresentados conceitos de startups. Em seguida são descritos, em sequência, conceitos de gestão do conhecimento, conhecimento crítico e estratégias de inovação. Após a fundamentação teórica que dará suporte à pesquisa, detalham-se os procedimentos metodológicos, os resultados esperados e, por fim, a conclusão.

\section{STARTUPS}

Segundo Silva (2013) a definição de startup está relacionada a três critérios: ser uma empresa de dimensão pequena ou média, estar nos primeiros estágios de desenvolvimento e possuir um elevado grau de inovação e risco. Para Blank e Dorf (2014) é uma organização temporária projetada para buscar um modelo de negócio repetível e escalável que opera em um meio de incerteza. Por estarem ligadas à inovação, as startups, têm perspectivas elevadas de retornos futuros, entretanto, por se tratar de um setor ligado diretamente ao risco e de empresas que normalmente não estão acostumadas ao mercado que estão explorando, estes retornos dependem da sobrevivência da empresa e da aceitação do projeto pelo mercado. Exemplos de startups que podemos citar como referências no mercado são Google, Netflix, PauPal e a brasileira EasyTaxi.

Blank (2006) apresenta um modelo de desenvolvimento de produto de startups, passando por quatro etapas:

1. Concepção é o momento de definição do produto ou serviço que a startup vai oferecer, se essa ideia é passível de aplicação no mercado, qual o público alvo e onde a empresa vai encontrá-lo;

2. No desenvolvimento do produto a empresa já tem o produto definido então divide suas funções para iniciar o desenvolvimento da inovação;

3. Teste alpha/beta é o momento onde é selecionamento um grupo de possíveis clientes para utilizar o produto e observar possíveis falhas do sistema;

4. Lançamento do produto iniciando o processo de comercialização. Entretanto, o cumprimento dessas etapas não é garantia de uma startup de sucesso, por se tratar de um mercado extremamente mutável existem alterações ou falhas que podem transcorrer ao decorrer do desenvolvimento do produto ou no processo de vendas.

Blank (2006) divide as startups em quatro tipos de acordo com sua existência no mercado ou seu modo de entrada no mercado. 0 primeiro tipo desenvolve novos produtos e atuam em um mercado já existente; o segundo consiste em um novo produto que origina um novo mercado; o terceiro um novo produto que atua em um mercado já existente e ressegmentação de baixo custo; e o quarto consiste em um novo produto, em um mercado já existente e ressegmentação em um nicho do mercado.

A estratégia na formação e desenvolvimento de uma startup é um ponto primordial (que 
autores afirmam isso?). Para Steve Blank (2006) uma startup precisa investigar o cliente e o mercado antes de desenvolver suas alternativas, pois, é isso que diferencia os vencedores dos derrotados. Conforme Silva (2013) a literatura destaca que o insucesso da startup pode estar relacionado diretamente com causas internas da organização, ou seja, o que discrimina uma empresa vitoriosa é o modo com que ela se desenvolve e se relaciona com o contexto externo. Ter um conhecimento dos caminhos a serem seguidos no mercado para obtenção de clientes e com isso alcançar o desejado sucesso pelos fundadores de startups não é garantia, a gestão de como será utilizado e difundido o conhecimento e o planejamento que deve ser seguido pela empresa são fatores que influenciam o futuro da empresa.

\section{GESTÃO DO CONHECIMENTO}

Perez-freije e Enkel (2007) afirmam que a velocidade das mudanças são um dos fatores que levam as organizações a terem uma necessidade de inovação contínua. Ermine (2007) identifica o conhecimento como um dos principais elementos estratégicos utilizados pelas organizações em resposta ao novo ambiente onde a economia se encontra, pois, o modo como as empresas clássicas atuavam é afetado pela estrutura existente atualmente no meio organizacional.

Segundo Nonaka e Takeuchi (1997, p. 1) "por criação do conhecimento organizacional entende-se a capacidade de uma empresa de criar novo conhecimento, difundi-lo na organização como um todo e incorporá-lo a produtos, serviços e sistemas". Entretanto, Nonaka e Takeuchi (1997) destacam que o conhecimento não pode ser formulado pela empresa, ele é criado pelos indivíduos, a organização incentiva a criação do conhecimento pelo profissional e depois este difunde esse conhecimento na organização.

Nonaka e Takeuchi (1997) dividem o conhecimento como tácito (experiência) e explícito (racionalidade). Os autores destacam a existência de quatro modos de conversão do conhecimento: do conhecimento tácito em conhecimento tácito (socialização); do conhecimento tácito em conhecimento explícito (externalização); do conhecimento explícito em conhecimento explícito (combinação); e do conhecimento explícito em conhecimento tácito (internalização). Para Nonaka e Takeuchi (2008, p. 82) "uma empresa criadora de conhecimento não opera em um sistema fechado, mas em um sistema aberto, no qual o conhecimento é constantemente trocado com o ambiente externo". Segundo Dihl (2003) a gestão do conhecimento organizacional é composta por estratégias da empresa ou dos indivíduos para estabelecer meios de difundir ideias e experiências Estes, por sua vez, constituem o dito conhecimento, tanto individualmente quanto dentro dos processos ou práticas da organização.

\subsection{Conhecimento Crítico}

Nem todo conhecimento adquirido é necessário para a empresa, é importante que o gestor saiba quais conhecimentos são críticos para o funcionamento e crescimento da organização, e de que modo este conhecimento será armazenado.

A definição do que é critico para a organização é um assunto abordado por Ermine (2004). O autor afirma que a gestão do conhecimento é prejudicada por não conseguir analisar por completo o conhecimento disponível na empresa. Rus, Lindvall e Sinha (2001) abordam que a dificuldade de repasse vem do fato o conhecimento não ser armazenado como um todo, o que pode ser guardado são informações a respeito do conhecimento em questão.

Um modelo de mapeamento é demonstrado por Ermine (2004) para classificar as áreas de conhecimento da empresa de acordo com uma representação hierárquica. Segundo 
o autor estrutura é dividida com áreas que são estruturadas como: ponto central, que corresponde à finalidade principal da empresa; eixos do conhecimento, referentes à missão ou principais operações da empresa; temas de conhecimento; e domínios de conhecimento. O modelo inicia com áreas próximas da missão central da organização e segue até as áreas em seu entorno

Ermine (2004) distingue que o mapa obtido durante a fase de análise é que irá distribuir o conhecimento na empresa entre os diferentes setores de acordo com a missão da organização. Neste mapeamento são analisados quais conhecimentos são primordiais para o funcionamento da empresa. É a partir da localização e identificação do conhecimento obtido com o mapeamento que a empresa consegue alinhar seus objetivos estratégicos com o conhecimento existente.

\subsection{Inovação}

O conhecimento está ligado com a capacidade de inovação da empresa. Miguez (2012) destaca que ideias têm como matéria-prima o conhecimento, que é um ativo importante para as organizações. De acordo com autor é importante que a organização desenvolva um processo sistemático para a geração de ideias inovadoras, pois as empresas não podem depender apenas de ideias que surgem momentaneamente e sem um planejamento. 0 processo de inovação deve ser contínuo dentro da empresa, é indicado que a empresa disponibilize local e pessoal especializado, especificamente, para esta área de criação. Miguez (2012) destaca que para um processo contínuo de inovação dentro da organização deve-se cultivar e analisar o comportamento que auxilie no caminho de geração de ideias inovadoras e, com isso, propiciar o crescimento da empresa.

A inovação foi adquirindo um peso importante dentro da organização, como é descrito por Cormican e O'sullivan (2003). De acordo com os autores, a capacidade da empresa de crescer está diretamente ligada com a sua capacidade de gerar novas ideias e soluções e, a partir disso, explorá-los de maneira mais eficiente para o seu benefício, principalmente, em longo prazo. Portanto, o crescimento da empresa está, em parte, ligado ao modo com que é tratada a inovação em seu meio. As inovações organizacionais, além de produto e processos, podem atuar sobre o desempenho da firma como um todo, conforme destaca o Manuel de Oslo (2006), melhorando a qualidade, eficiência do trabalho, a troca de informações e a capacidade de aprender e utilizar tecnologias já conhecidas da organização.

\section{METODOLOGIA}

A pesquisa é considerada quali-quantitativa com o intuito de estruturar iniciativas de gestão do conhecimento voltadas para o incremento do processo de inovação em startups catarinenses, e será realizada conforme Figura 1.

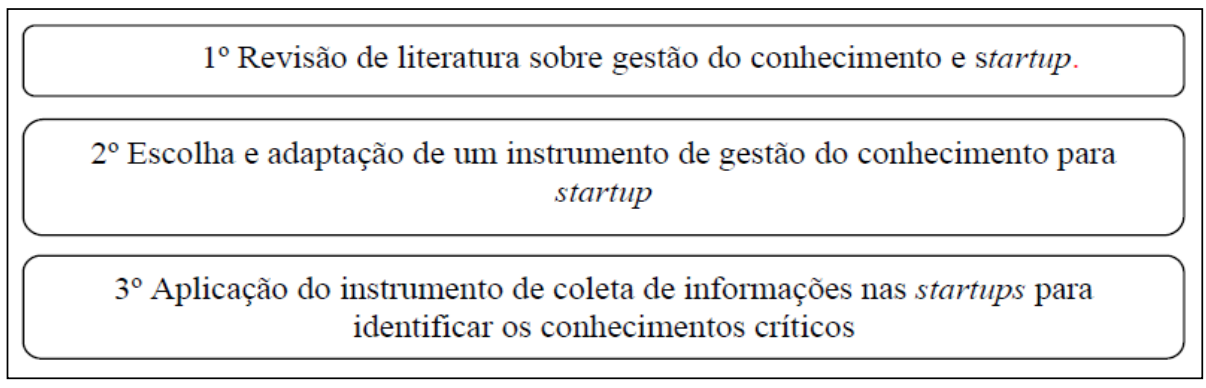

Figura 1: Procedimentos da pesquisa

Fonte: Elaborado pelos autores. 
Utilizar-se-á um questionário que será aplicado aos gestores das startups, onde as respostas podem ser assinaladas utilizando a escala Likert, que consiste em cinco possíveis respostas que podem ser assinaladas para se apurar de forma mais adequada a realidade de cada empresa. São elas: 1 - Concordo muito; 2 - Concordo; 3 - Neutro; 4 - Discordo; e 5 Discordo muito.

Com o intuito de identificar os conhecimentos críticos voltados para o processo de inovação nas startups estudadas foi escolhido como instrumento de pesquisa o Guia Europeu de Gestão do Conhecimento, com algumas adaptações voltadas para o contexto das empresas catarinenses.

\section{APRESENTAÇÃO DOS RESULTADOS}

A análise foi realizada a partir das respostas obtidas com a aplicação do questionário adaptada do Guia Europeu para Boas Práticas em Gestão do Conhecimento. O questionário foi respondido por seis gestores de diferentes empresas com diferentes áreas de atuação, $66,7 \%$ destes gestores possuem graduação completa ou em andamento, 16,7\% com ensino médio completo e 16,7\% com especialização. Todas as empresas estudas já atuam no mercado, com um mínimo de 1 ano e meio e o máximo de 26 anos. As empresas estudadas atuam nas cidades de Blumenau, Florianópolis, Joinville e Urussanga.

A Figura 2 demonstra as opiniões dos entrevistados em relação as características gerais de uma empresa como missão, a cultura, organização, entre outros.

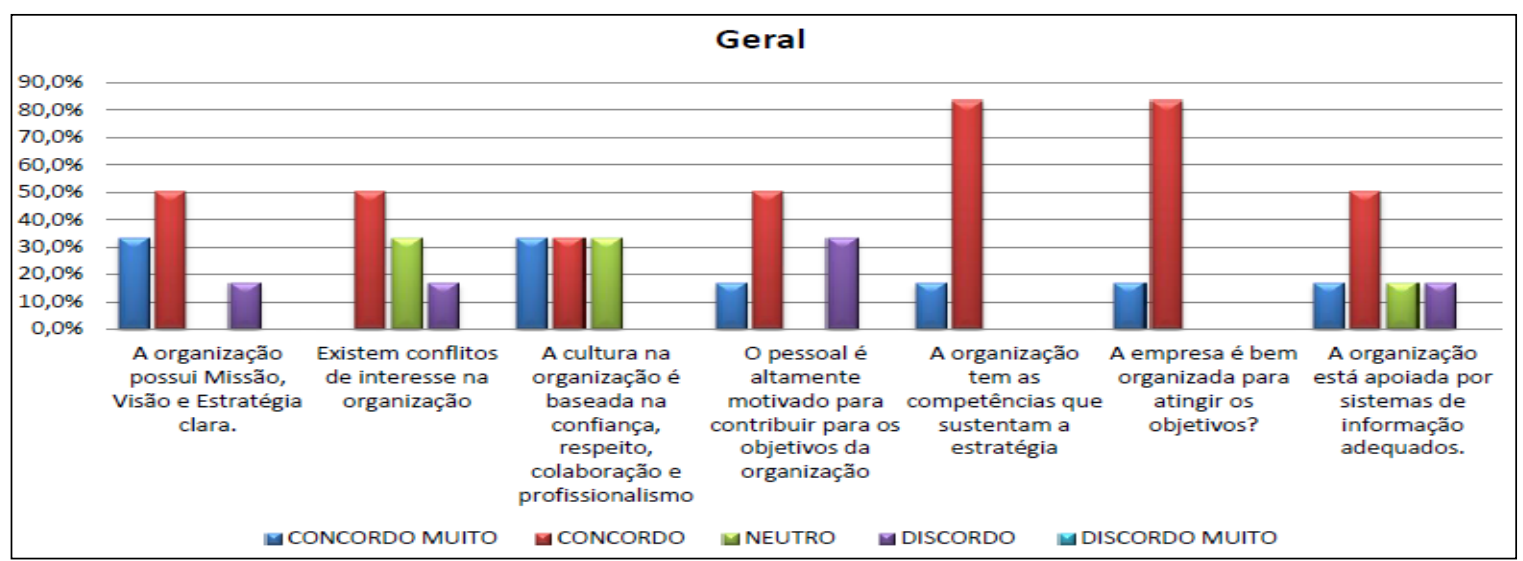

Figura 2: Características gerais das empresas

Fonte: Dados da pesquisa

Quando se trata da demonstração de forma clara da empresa que 83,3\% das respostas se mostram a favor, marcando concordo ou concordo muito, entretanto observamos que a metade dos entrevistados optou pela resposta concordo (50\%). Quando questionados sobre conflitos de interesse dentro da organização $50 \%$ dos entrevistados concordou com a existência desse fato, outros 2 entrevistados $(33,3 \%)$ permaneceram neutros ao assunto. Quando questionados sobre a base da cultural da organização ser composta por confiança, respeito, colaboração e profissionalismo, obtiveram-se $33,3 \%$ de respostas em concordo muito, concordo e neutro, o que demonstra que $66,7 \%$ das empresas acredita que a base da empresa deve ter esses quatro pilares. Quando se fala sobre motivação de pessoal para contribuição com os objetivos da empresa obtivemos metade das respostas (3), entretanto, 33,3\% das respostas (2) discordaram desse ponto.

A respeito das questões sobre a competência em sustentar seus objetivos e sobre a organização da empresa para alcançar seus objetivos obtiverem-se 83,3\% das respostas 
concordando, os outros 16,7\% optaram com concordo muito, em ambas as perguntas, não tendo, portanto, nenhuma resposta negativa nesses questionamentos. 0 último fator abordado da análise geral foi se o sistema de informação ao qual a empresa está apoiada é adequado, 50\% dos entrevistados concordaram com essa afirmação, os outros entrevistados se dividiram, em igual porcentagem (16,3\%), entre concordo muito, neutro e discordo muito.

Em uma segunda etapa buscou-se compreender a opinião dos entrevistados em relação a identificação do conhecimento dentro da organização, como podemos analisar na Figura 3.

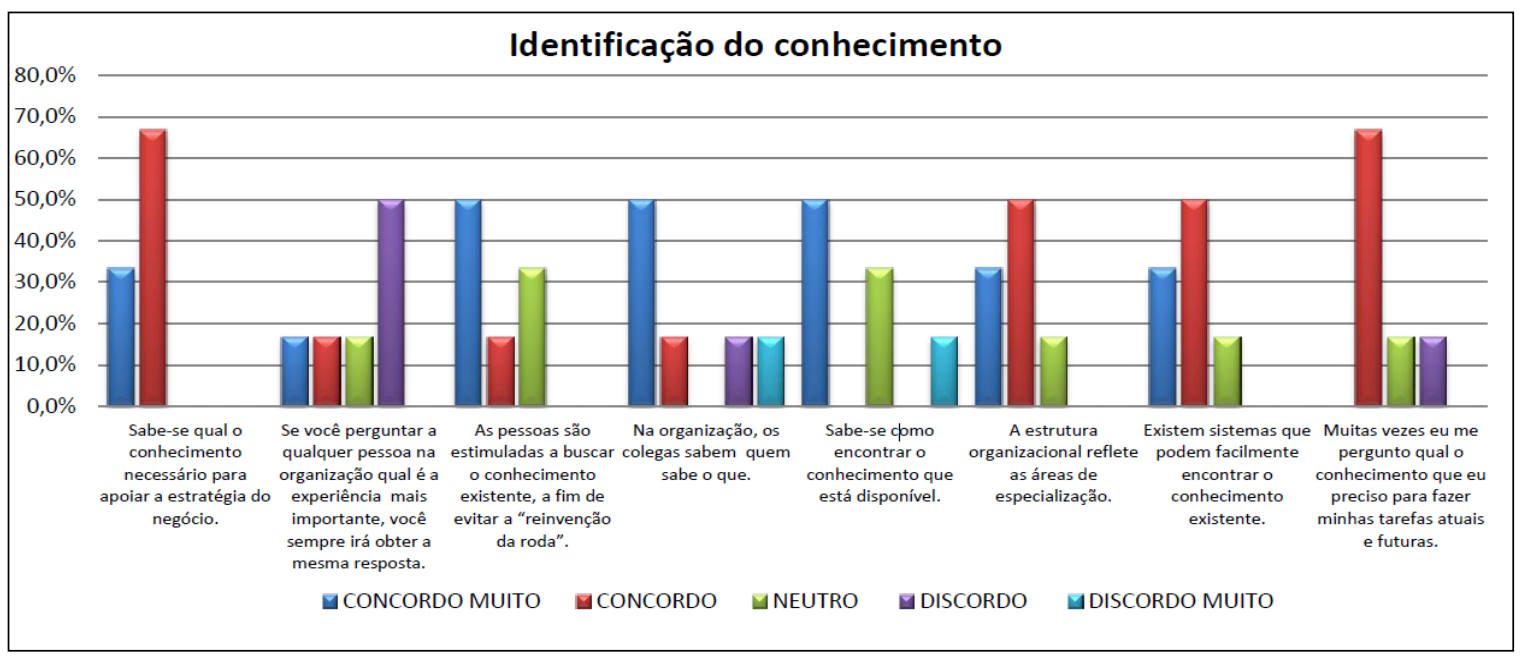

Figura 3: Identificação do conhecimento

Fonte: Dados da pesquisa.

Quando questionados se tem ciência do conhecimento necessário para apoiar a estratégia formulada pela empresa $66,7 \%$ afirmaram que concordam e o restante $(33,3 \%)$ assinalou que concorda muito. A questão que abordou se as pessoas da empresa tinham a mesma melhor experiência dentro da organização a maioria, no caso metade, apontou que discordava, o restante, $16,7 \%$ cada apontou que concordava muito, concordava e neutro. Ao questionar se as pessoas da organização eram estimuladas a buscar conhecimentos já existentes, $50 \%$ concordou muito.

Quando o assunto é se dentro da organização os funcionários sabem a quem recorrer sobre cada conhecimento $50 \%$ e $16,7 \%$ concorda muito e concorda, respectivamente. Quando questionados sobre a praticidade que se tem de encontrar o conhecimento existente dentro da empresa 50\% concorda. Perguntando se estrutura da organização reflete áreas de especialização obteve-se apenas respostas positivas ou neutras, com $50 \%$ dos entrevistados informando que concordam. 0 mesmo foi verificado no questionamento sobre a existência de um sistema que facilite o encontro do conhecimento já existente. Quando a pergunta é direcionada a necessidade do próprio entrevistado se perguntar sobre qual conhecimento ele deve usar para as tarefas a serem realizadas observamos que $66,7 \%$ concordam que se perguntam muitas vezes sobre qual e como utilizar.

Na Figura 4 observamos as respostas referentes a criação de conhecimento das empresas entrevistadas, relacionado principalmente com as inovações. 


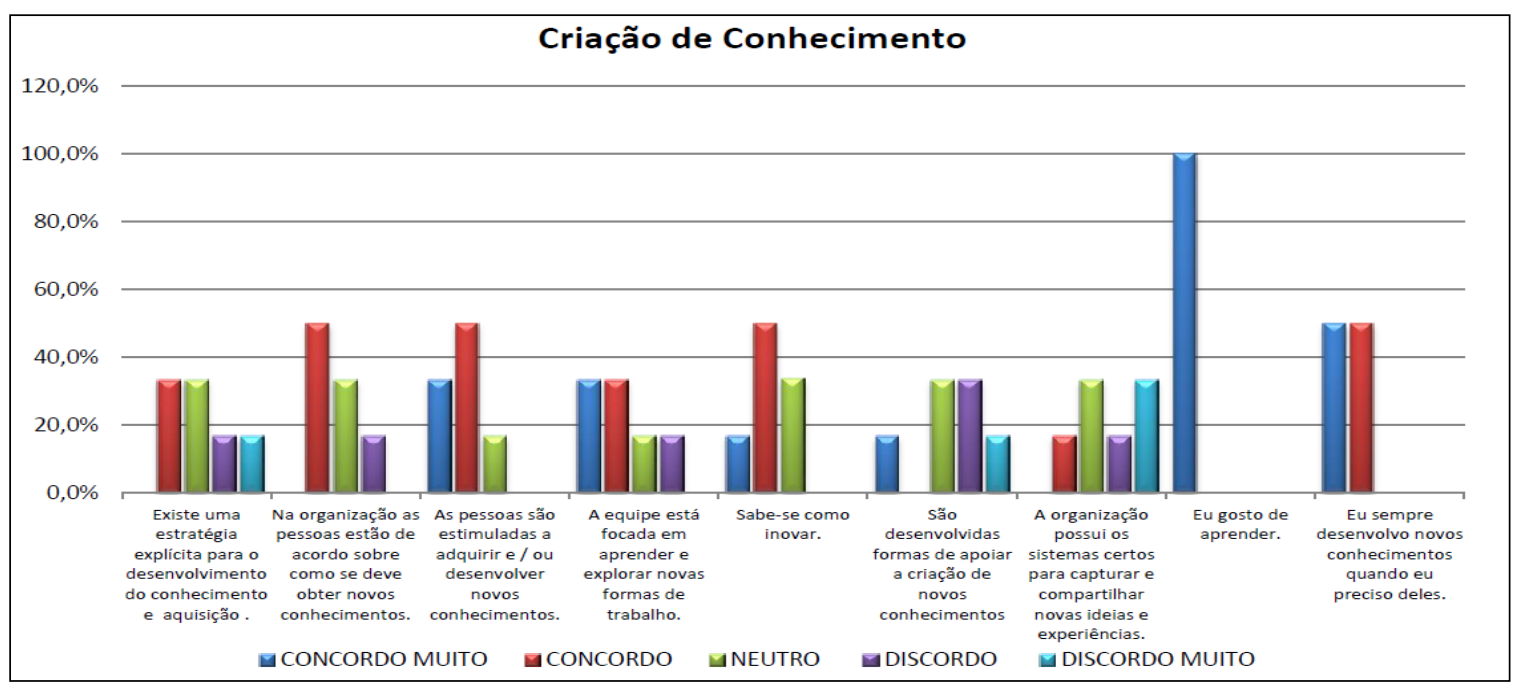

Figura 4: Criação do conhecimento

Fonte: Dados da pesquisa.

O questionário inicia com a pergunta relacionada a existência de uma estratégia clara de desenvolvimento e aquisição de conhecimento onde as repostas concordo e neutro ficaram cada uma com 33,3\% das respostas, discordo e discordo muito ficaram com os outros 33,3\% (16,7\% cada). A pergunta relaciona a concordância das pessoas ao modo como se deve obter novos conhecimentos na organização representou nas respostas com $50 \%$ concordam, o restante das respostas se divide entre neutro (33,3\%) e discordo $(16,7 \%)$. Obtemos 83,3\%, concordo muito (33,3\%) e concordo (50\%), de respostas quando o questionamento se referiu a existência de estímulos para adquirir ou desenvolver conhecimentos novos.

Questionados se o grupo está focado em aprender/explorar novas formar de trabalho 66,6\% (33,3\% concordam muito e 33,3\% concordam) de respostas afirmativas. Quando questionados se a empresa sabe como inovar, $50 \%$ responderam de forma afirmativa com o concordo. Recebemos respostas negativas quando interrogado se existe $o$ desenvolvimento de formas de apoio a criação de novos conhecimentos, $50 \%$ discorda ou discorda muito desse ponto (33,3\% e 16,7\% respectivamente), enquanto $33,3 \%$ se mantêm neutro a essa questão. 50\% de respostas negativas (discordo e discordo muito, 16,7\% e $33,3 \%$ respectivamente) também foram obtidas quando o assunto era a existência de um sistema corretos para a captura e compartilhamento de ideias e experiência, outros 33,3\% ficaram neutros a essa questão. 0 gosto por aprender foi respondido com a máxima afirmativa (concordo muito) por $100 \%$ dos entrevistados. Eles ficaram divididos entre concordo muito e concordo ( $50 \%$ cada) quando o tema foi se estes desenvolvem novos conhecimentos quando existe uma necessidade para a função deles.

Na Figura 5 tenta-se compreender como este conhecimento é armazenado dentro das organizações pesquisadas. 


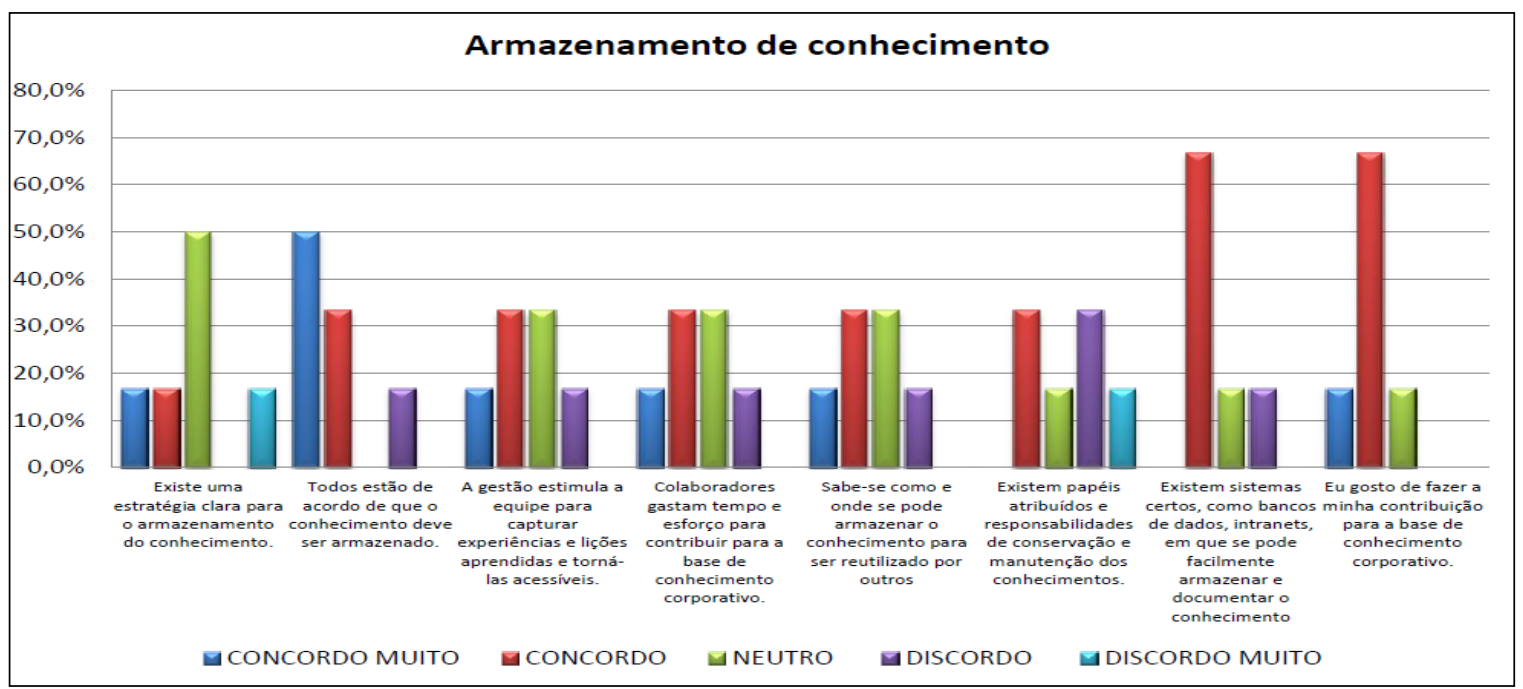

Figura 5: Armazenamento de conhecimento

Fonte: Dados da pesquisa.

A primeira pergunta se referia a clareza nas estratégias da empresa em armazenar o conhecimento onde a maioria das respostas foi neutro (50\%), seguido por concordo muito, concordo e discordo, todas elas com 16,7\%. Perguntados se todos concordam que o conhecimento deve ser armazenado, 50\% concordam muito com esse fato e 33,3\% assinalaram que concordam (83,3\% de respostas positivas).

$\mathrm{Na}$ questão sobre se a gestão estimula a captura e compartilhamento de conhecimento $33,3 \%$ concordam enquanto outros $33,3 \%$ se disseram neutro a essa pergunta. A mesma resposta foi obtida quando se refere a questão de os colaboradores auxiliarem na construção da base de dados de conhecimento da empresa, 33,3\% concordam enquanto outros 33,3\% se disseram neutro. Outra vez se obteve a resposta 33,3\% concordam e 33,3\% neutros quando o questionado se é notório como e onde o conhecimento pode ser armazenado.

A maioria das respostas, quando questionado da existência de papéis e responsabilidades de conservação e manutenção conhecimento, foi contraditória, pois, $33,3 \%$ informaram que concordavam com essa conduta e 33,3\% assinalaram como discordam. Referente a existência de banco de dados para documentar e armazenar o conhecimento 66,7\% (concordam) confirmam a existência. Da mesma forma 66,7\% dos entrevistados concordaram com o fato de eles mesmos fazerem contribuição para a base de conhecimento da organização.

A Figura 6 é formado pelas respostas sobre compartilhamento de conhecimento. 


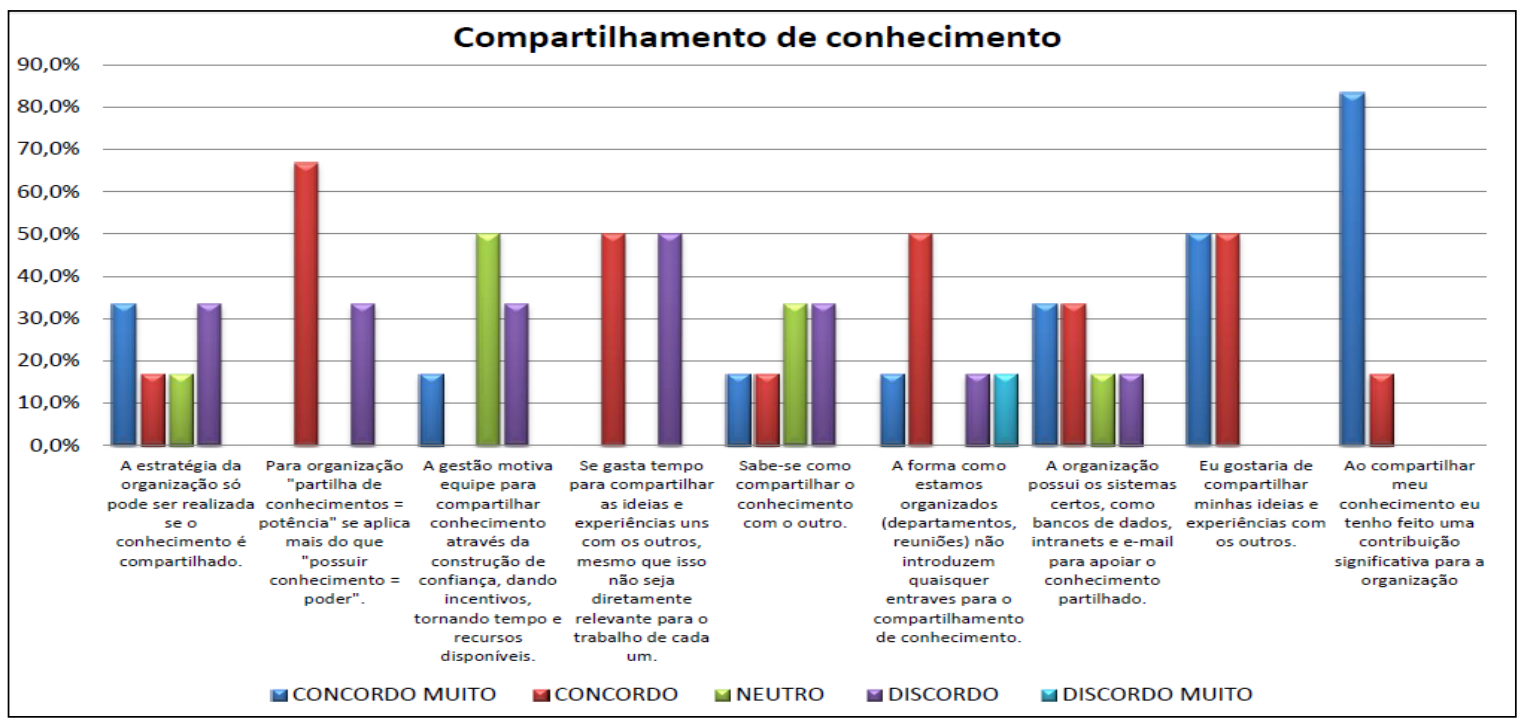

Figura 6: Compartilhamento de conhecimento

Fonte: Dados da pesquisa.

0 primeiro questionamento aborda se na opinião dos entrevistados a estratégia da organização pode apenas ser atingida se o conhecimento é utilizado de modo compartilhado, nessa questão 33,3 \% afirmou que sim, concorda muito, em contrapartida, outros 33,3\% discordam desse posicionamento. A opinião dos entrevistados sobre a partilha de conhecimento ser mais aplicada que o fato de possuir o conhecimento, onde $66,7 \%$ concordam e o restante $(33,3 \%)$ discorda.

Sobre a motivação para que a equipe compartilhe seu conhecimento $50 \%$ se manteve neutro. A existência de tempo gasto para compartilhamento de ideias e experiências (mesmo essas não estando ligadas diretamente ao trabalho) existiu divergência, onde $50 \%$ concordaram e os outros $50 \%$ discordaram com a existência. Referende a equipe saber como compartilhar o conhecimento entre si $33,3 \%$ se manteve neutros e outros 33,3\% discordaram. Foi questionado também sobre a possibilidade de o modo da empresa estar organizada não atrapalharem o compartilhamento do conhecimento, o que foi afirmado pela maioria dos entrevistados onde $50 \%$ concordaram e $16,7 \%$ concordaram muito. $66,6 \%$ (33,3 concordando muito e 33,3\% concordando) afirmaram que possuem sistemas para apoiar o armazenamento de conhecimento. Quando questionados sobre a vontade de compartilhar as experiências com os outros obteve-se $100 \%$ de afirmação, onde $50 \%$ marcaram concordo muito e os outros $50 \%$ concordo. Em seguida foi questionado se o compartilhamento do conhecimento dos entrevistados tem contribuído positivamente para a empresa, 83,3 concordaram muito com a existência dessa contribuição e o restante $(16,7 \%)$ se manteve no concordo.

A Figura 7 mostra as respostas referentes a aplicação do conhecimento adquirido pelas empresas 


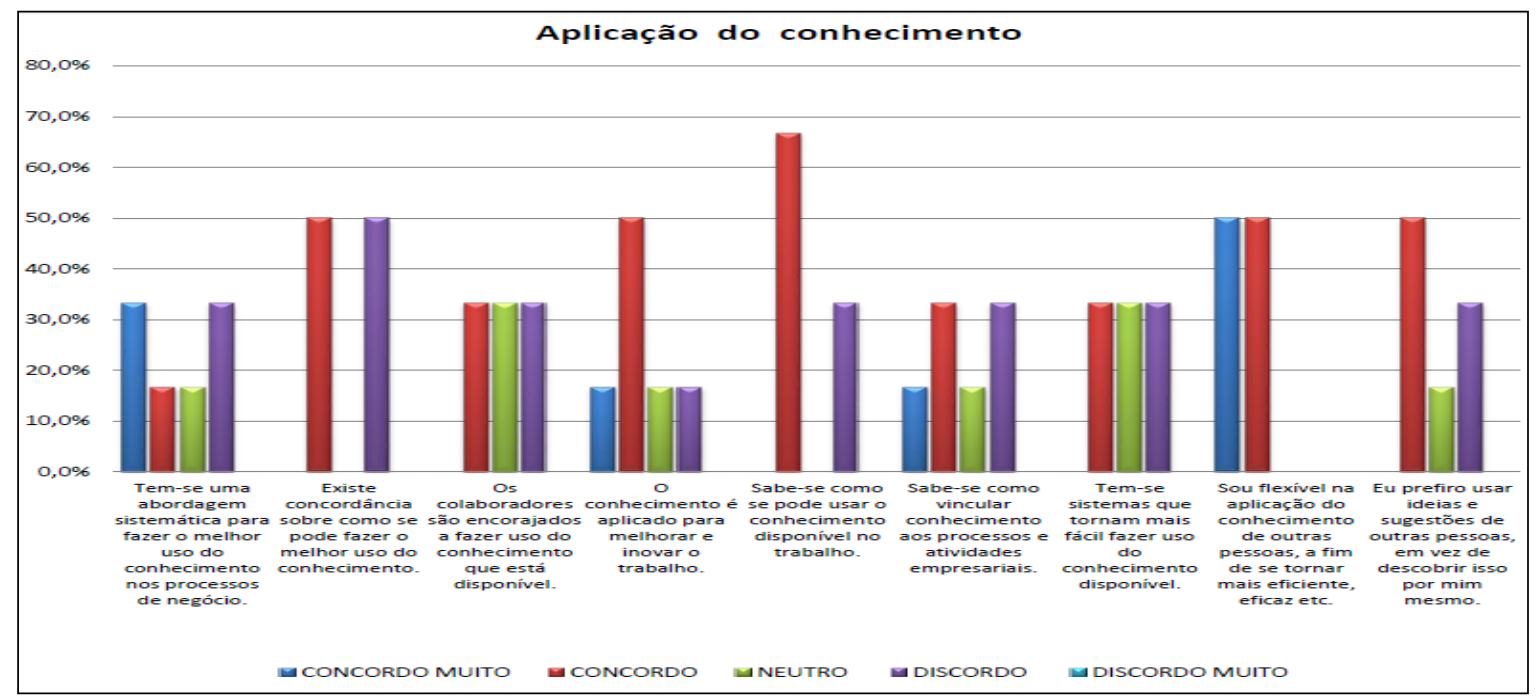

Figura 7: Aplicação do conhecimento

Fonte: Dados da pesquisa.

Inicia-se com a questão sobre a existência de uma abordagem sistemática para o melhor uso do conhecimento nos negócios da empresa, onde 33,3\% concordam muito e outros 33,3\% discordam dessa existência. Quanto tratou-se sobre a existência de uma concordância no melhor modo de usar o conhecimento tem-se uma discordância, onde $50 \%$ concordam e $50 \%$ discordam. Os entrevistados foram questionados também se existe um encorajamento aos colaboradores utilizarem o conhecimento disponível na empresa, onde $33,3 \%$ concordaram e 33,3\% discordaram da existência, os outros entrevistados se mantiveram neutros nessa questão. Questionados se esse conhecimento é aplicado para melhor e inovar o trabalho 50\% respondeu que concorda com essa aplicabilidade. Perguntou-se então se compreende como usar esse conhecimento disponível na organização, as respostas foram em sua maioria positiva (concordo $66,7 \%$ contra discordo $33,3 \%)$.

Já quando questionados se se tem conhecimento de como vincula-lo aos processos e atividades da empresa, 33,3\% concordaram e outros 33,3\% discordaram. No tema sobre a existência de um sistema para facilitar o uso do conhecimento foi respondido na mesma proporção concordo, neutro e discordo, com 33,3\% cada. No cunho pessoal, os entrevistados responderam se são flexíveis à aplicação de conhecimento de outras pessoas, onde se teve uma resposta positiva, $50 \%$ concordam muito e $50 \%$ concordam. Uma segunda pergunta pessoal foi se existe uma preferência, pelo entrevistado, a utilizar ideias e sugestões de terceiros em vez de formula-las por conta própria, 50\% doa entrevistados concordaram, enquanto $33,3 \%$ discordaram.

A Figura 8 aborda questões sobre o controle do conhecimento que a empresa possui. 


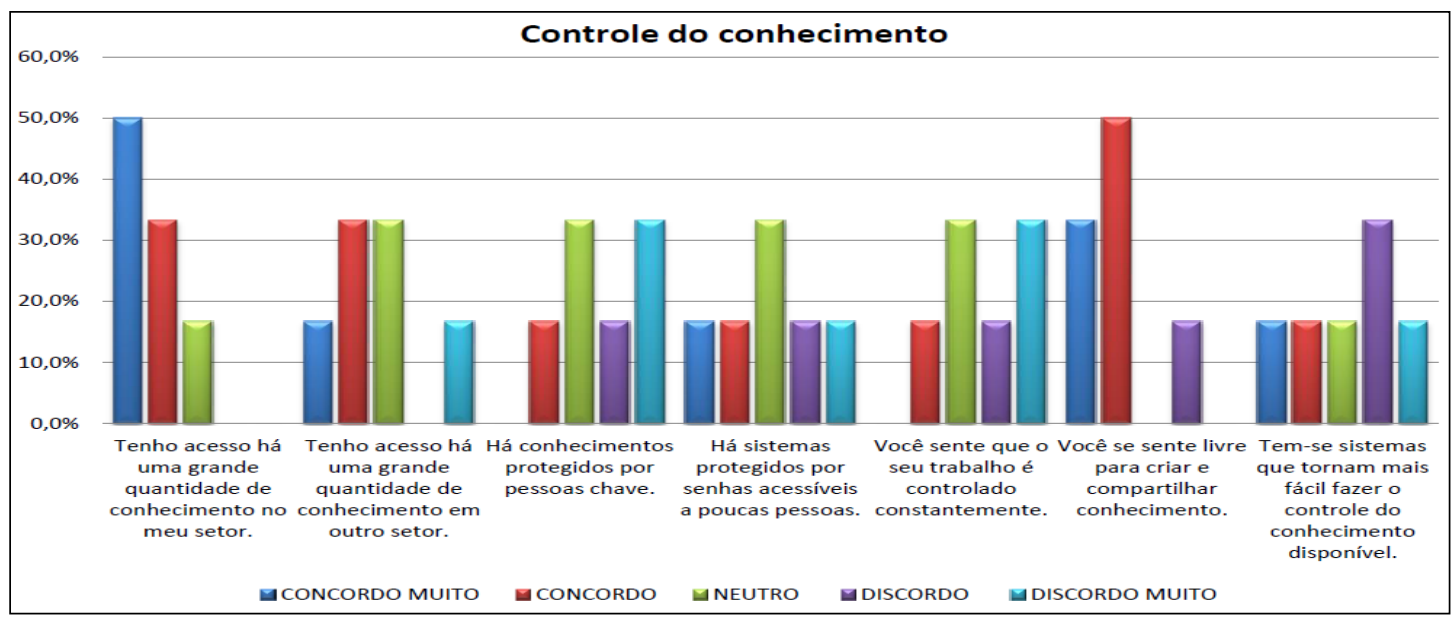

Figura 8: Controle do conhecimento

Fonte: Dados da pesquisa.

De início é indagado se o entrevistado tem acesso a uma grande quantidade de conhecimento do seu setor de atuação, onde 50\% concordam. Quando a mesma pergunta é realizada, mas se referindo a conhecimento de outros setores $33,3 \%$ concordam, enquanto $33,3 \%$ permanecem neutros. Há existência de conhecimento protegido dentro das empresas consultadas foi respondido com 33,3\% de mantando neutro e outros 33,3\% discordando muito. Obteve-se respostas bem diferentes quanto o tema foi a existência de sistemas protegidos, utilizados por poucos indivíduos da organização, onde 33,3\% se mantiveram neutros, e concordaram muito, concordaram, discordaram e discordaram muito $16,7 \% \mathrm{em}$ cada. Sobre a sensação do trabalho ser controlado constantemente, os entrevistados, 33,3\% responderam que discordam muito enquanto outros 33,3\% se mantiveram neutros. Sobre a sensação de liberdade para criar e compartilhar conhecimento as respostas foram positivas, $50 \%$ concorda e 33,3\% concorda muito com esse fato. Questionados sobre a existência de um sistema que facilite o controle do conhecimento disponível as respostas voltaram a ser espaçadas, $33,3 \%$ discordam e o restante se divide em concordo muito, concordo, neutro e discordo muito (16,7\% cada).

A Figura 9 questiona sobre a comunicação do conhecimento dentro da empresa.

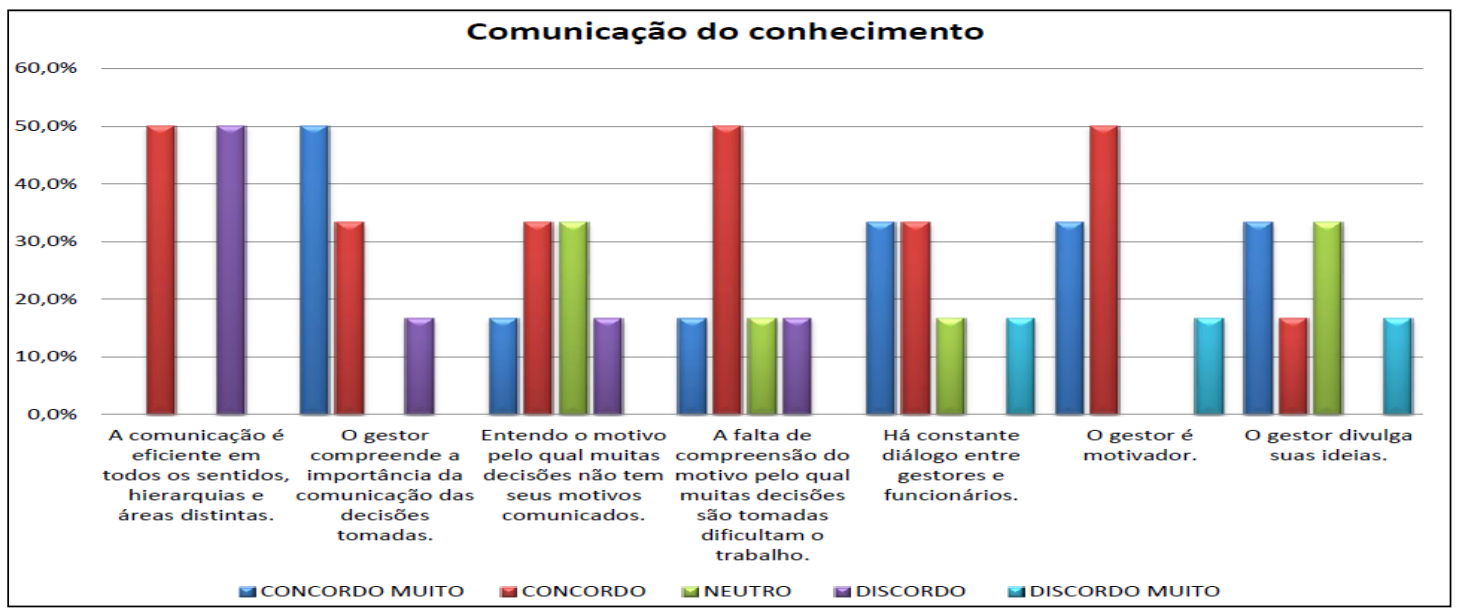

Figura 9: Comunicação do conhecimento

Fonte: Dados da pesquisa. 
Os entrevistados são questionados se a comunicação do conhecimento atinge, de forma eficiente, os níveis hierárquicos e diferentes áreas da empresa, onde 50\% concordaram e o restante (50\%) discordou dessa abrangência. Ao serem perguntados se o gestor entende a importância da comunicação das decisões tomadas, 83,3\% das respostas são positivas ( $50 \%$ concordam muito e $33,3 \%$ concordam). Quando o tema é a compreensão dos dos motivos que levam muitas decisões não serem comunicadas, 33,3\% (concorda) entende e outros 33,3\% se mantiveram neutro nesse ponto. Quando questionados se a falta de compreensão sobre algumas decisões tomadas dificulta o trabalho, a maioria concordou $(50 \%)$ ou concorda muito $(16,7 \%)$. Foi questionado sobre a existência de um frequente diálogo entre gestores e funcionários, onde $66,6 \%$ responderam de forma positiva $(33,3 \%$ concordam muito e 33,3\% concordam). Questionados sobre o gestor ser inovador, $50 \%$ concordou e 33,3\% concordou muito. Em outro ponto, perguntado se o gestor divulga suas ideias $33,3 \%$ concordaram muito e outros $33,3 \%$ se mantiveram neutros.

\section{ANÁLISE E DISCUSSÃo DOS RESULTADOS}

Os gestores entrevistados concordam da visão de Nonaka (1991), onde o autor aponta que o único conhecimento que as empresas acreditam ser útil é o formal e sistemático, levando em consideração os critérios de mensuração quantificáveis como maior eficiência, menor custo e maior retorno do investimento. A resposta obtida demonstra que na maioria dos casos analisados onde o conhecimento é uma estratégia necessária para a organização na estratégia de negócio, os gestores, em sua maioria, concordaram fortemente que o conhecimento deve ser conhecido por todos do setor e que esse conhecimento deve ser repassado para outros setores, como visto na Figura 8.

Para Rus, Lindvall e Sinha (2001) o conhecimento é enriquecido quando valorizado e não diminui com o uso, o compartilhamento deve ser feito através da externalização da informação e da internalização do conhecimento. Fialho et al. (2005) considera que o crescimento da tecnologia de informação e comunicação desenvolve na economia as habilidades de manipular, armazenar e transmitir demasiada quantidade de informação com custos próximos de zero, o que facilita a implantação do conhecimento às atividades econômicas dos mais diversos setores. Nesse sentido, os entrevistados, foram questionados sobre a existência de um sistema para facilitar o controle do conhecimento, onde responderam que discordam dessa existência na organização, mas concordaram fortemente com a existência de uma abordagem sistemática para o uso do conhecimento.

Segundo Fialho et al. (2005) a Gestão do Conhecimento deve conter diversas tecnologias para auxiliar a lidar com os diferentes modelos (gráficos, textos, documento, etc) de informação que podem ser utilizados no armazenamento de conhecimento e ajudar na sua distribuição, neste sentido, os gestores concordam com o autor ao demonstrarem a existência de um sistema que auxilia na busca dessas informações na empresa.

Canongia et al. (2004) e Nonaka (1991) afirmam que em uma economia formada por incertezas a fonte mais segura de obter vantagens competitivas é o conhecimento, que pode ser obtido das mais diferentes maneiras, o que é uma forma seguida pelas empresas já que a maior parte dos entrevistados concordou que existem estímulos para descobrir novos conhecimento, e que o conhecimento é desenvolvido também quando precisam dele. Concordaram ainda fortemente com o incentivo para pesquisar conhecimentos já existentes a serem implantados na empresa. A necessidade de busca sistemática de inovações radicais e incrementais é um dos pontos destacados por Canongia et al. (2004) como fator fundamental para sobrevivência da empresa, os gestores, durante o questionário, demonstraram concordar com esse apontamento, eles concordam, como visto na Figura 4, 
com a existência de estímulos a novos conhecimentos e novas formas de trabalho, mas discordam que exista uma forma de apoio a criação de conhecimento.

A competitividade não se caracteriza apenas no desempenho, eficiência técnica ou produtos, Canongia et al. (2004), levantam que também se trata da capacidade de desenvolver processos buscando novas oportunidades, superar os obstáculos técnicos e organizacionais através da produção e da aplicação do conhecimento. A pesquisa demonstrou que além da busca pela criação de conhecimento, em sua maioria, também incentivam a procura de conhecimentos já existentes no mercado para serem implantados, eles afirmam que as pessoas da empresa concordam com o modo de obter novos conhecimentos para utilização da organização. A medida que o tempo passa a produção artesanal se transforma em engenharia, isso ocorre com o crescimento e desenvolvimento dos projetos de software, segundo Rus, Lindvall e Sinha (2001). Os autores constatam que com isso o conhecimento individual deve ser compartilhado dentro da organização e formulado em estratégia de como ela irá alcançar o nível de projetos e a organização, como prega a gestão do conhecimento. Fialho et al. (2005) afirma que a estratégia é o modo da organização administrar seus recursos, capacidades e competências de modo a alcançar seus objetivos. Os gestores concordam com o fato de sustentarem uma estratégia e também de trabalharem com ela para atingir seus objetivos.

A estratégia da empresa é elaborada na alta administração, porém deve ser comunicada e implantada em conjunto com todos os funcionários da organização. Canongia et al. (2004), afirmam que toda empresa, sabendo ou não, adota estratégias, já que a escolha por não formular uma estratégia é entendida como uma estratégia segundo o autor. Nos questionários os gestores apontaram que discordam que a mesma experiência seja dada a todos da empresa, mas concordam com é dado estimulo a captura de experiências e lições. Camargo e Dias (2010, p. 38) destaca que a "atuação dos funcionários como colaboradores é necessária em razão do caráter transitório e adaptativo dessa estratégia, que é um processo contínuo e propenso a mudanças e adequações". Os gestores compartilham dessa afirmação do autor, eles concordam que os colaboradores contribuem com o conhecimento para a empresa e discordam fortemente que os colaboradores devem ter seu trabalho controlados constantemente, eles devem ser livres para criar conhecimento, como visto na Figura 8.

Segundo Fialho et al. (2005, p. 23) "ao traçar uma estratégia na organização, o administrador determina objetivos e metas, bem como define linhas de ação e alocação de recursos necessários", os entrevistados concordam com o ponto, tem estratégias explicitas de desenvolvimento. Segundo o autor a estratégia deve ser formulada em um ambiente aberto, em um processo participativo, com um eficiente fluxo de comunicação, compartilhamento de informações, em linguagem adequada e em todos os níveis da organização.

Levantando o ponto de uma boa estratégia e boa comunicação os entrevistados responderam que concordam fortemente que na empresa se sabe quem sabe o que, e concordaram que se sabe onde armazenar o conhecimento e que sabe-se como utiliza-lo, mas também concordaram que as vezes se perguntam o que deve ser feito a seguir, ainda não tem toda a estratégia da tarefa futura formulada. Dyer e Nobeoka (2000 apud Alcará et al. 2009) enfatizam a necessidade do compartilhamento de informações, auxiliada com motivações e interações sociais, os gestores, nesse tópico, se mantiveram neutros aos incentivos por meio de confiança, e se dividiram em concordar e discordar da existência de um tempo para partilhar ideias dos colaboradores, mesmo que essas ideias a principio não sejam tão relevantes. Os autores listam que para essa integração ser maximizada a clareza dos objetivos da organização, o uso de linguagens comuns para classificação dos tipos e funções, participação em eventos sociais (aumento de contatos) e disposição estratégica 
geográfica do indivíduo para compartilhamento de informação em rede (fator com menor necessidade atualmente com os meios de comunicação facilitadores). Os entrevistados se conciliam a ideia do autor ao concordar fortemente que a estratégia de empresa só é realizada se o conhecimento é compartilhado, com a existência de bancos de dados, e-mails, entre outros para partilhar conhecimento e que as contribuições dos colaboradores são significativas para a organização. Entretanto, o gestor discorda que se sabe como compartilhar esse conhecimento, mas, como visto na Figura 6, concorda que que a forma de organização de compartilhamento de sua empresa está correta.

A afinidade entre os colaboradores, a empresas e sua missão é um dos pontos para o compartilhamento do conhecimento, segundo Nonaka (1991), pois o conhecimento individual convertido em conhecimento organizacional é utilizado por toda a empresa, os entrevistados concordam que a missão e visão da empresa são passadas de forma clara, os gestores se desacordam (concordam, ficam neutros e discordam) na existência de encorajamento para os colaboradores usarem o conhecimento disponível, concordam também com a existência de conflito de interesses dentro da organização. Como Alcará et al. (2009, p. 175) ratificam, "o processo de comunicação é inerente às atividades científicas, e o contato entre os profissionais torna-se indispensável para desencadear o fluxo da informação e do conhecimento". Os gestores, sobre o tema, responderam que concordam fortemente que o gestor sabe e deve saber passar as decisões da empresa e concordam com o fato da falta de compreensão atrapalhar o andamento da organização. Os gestores entrevistados concordam/concordam fortemente que existe dialogo entre o gestor e os funcionários, concordam que o pessoal é motivado e que essa motivação parte também do gestor e concordam fortemente com o ponto levantado de que a gestor deve divulgar suas ideias. Nonaka (1991) destaca que o insight da criação pode partir de um pesquisador brilhante ou de um operário de fábrica, e que cabe ao gerente de nível médio tornar-se o catalisador a partir de sua intuição de mercado.

Os empregados de linha de frente estão imersos nos detalhes cotidianos das tecnologias, produtos ou mercados específicos. Ninguém compreende tanto quanto eles a realidade dos negócios da empresa. No entanto, embora recebam uma enxurrada de informações altamente específicas, esses empregados quase sempre acham extremamente difícil converter tais informações em conhecimentos úteis (NONAKA, 1991, p. 7).

Tonet e Paz (2006) afirmam que o compartilhamento de conhecimento necessita de uma linguagem comum entre os atuantes na organização para acontecer, os autores concordam com Nonaka (1991) ao constatarem que esse é um dos grandes obstáculos na empresa, os gestores concordam que os colaboradores sabem como encontrar esse conhecimento a disposição. Segundo Sveiby (1998) o entendimento de uma pessoa não tem o mesmo significado que o outro buscava expressar, os gestores concordam que o conhecimento deve ser armazenado, mas discordam que exista pessoal responsável para conservar e fazer manutenção sobre esse conhecimento. A conversão do conhecimento tácito em explícito é uma das tarefas gerenciais importantes, entretanto, seu cumprimento necessita de ferramentas, segundo Nonaka (1991), a linguagem figurativa e o simbolismo são utilizados para aperfeiçoar o modo de expressar o conhecimento obtido.

Para demonstrar que a competição também é um modo de incentivo aos colaboradores, Nonaka (1991), comenta sobre o modo que empresas japonesas fazem essa abordagem com o "princípio da competição interna". Ele descreve que a empresa divide os funcionários em equipes e as equipes de subdividem em grupos que serão concorrentes, os grupos, trabalharam no mesmo projeto, cada um irá desenvolver uma abordagem diferente 
que posteriormente serão discutidas pela equipe. Nonaka (19991) destaca que isso estimula a encarar cada projeto sob uma variedade de perspectivas, e assim desenvolvem uma visão comum sobre a "melhor" abordagem, os gestores concordam que partilhar o conhecimento é potencializar sua capacidade e que os gestores concordam que contribuem com o conhecimento e gostam de partilhar suas ideias e aprender com terceiros, como visto nas Figuras 6 e 4 .

0 mercado impõe certas exigências que levam as organizações a terem mudanças sistemáticas, generalizadas para se adequar ao mercado, segundo Fialho et al. (2005), as organizações podem se adaptar ou criar novas práticas para isso. Os gestores concordam que aplicam o conhecimento para melhorar e inovar no trabalho e que sabem como vincular o conhecimento com as atividades da empresa e concordam com o ponto de a estrutura organizacional refletir a área de especialização da empresa. Entretanto, Tonet e Paz (2006, p. 79) destacam que,

\begin{abstract}
Em grande parte das organizações, os procedimentos vigentes não permitem flexibilização das rotinas, ou adaptações a demandas específicas; muitas vezes, tais procedimentos visam exatamente a manter sem alterações a forma de execução das atividades, e preservar as situações operacionais existentes. Dificilmente as pessoas são encorajadas a reexaminar as suas rotinas de trabalho e a combater os procedimentos operacionais ineficazes.
\end{abstract}

Os gestores se mantêm neutros a existência de conhecimento protegido por senhas e discordam fortemente que existam conhecimentos protegidos por pessoas especificas. A confiança possibilidade a integração entre os colaboradores, é um fator primordial para que o conhecimento aconteça de forma eficaz e satisfatória segundo Alcará et al. (2009), em paralelo os gestores concordam/concordam fortemente que a cultura da empresa é baseada na confiança. 0 autor destaca que alguns elementos podem auxiliar na motivação de compartilhar conhecimento, exemplos seriam confiança, amizade, afinidade, harmonia e doação. Esses são laços criados com o tempo e que não dependem de incentivos externos, já que envolve outros fatores como valores, crenças, sentimentos e interesses em comum. Em relação a isso os gestores discordam fortemente que existe um sistema para captura e compartilhamento de ideias, não existe uma interferência direta da empresa nesse sentido.

\title{
7 CONSIDERAÇõES FINAIS
}

Uma boa gestão dos conhecimentos da empresa, incentivos a inovação e estímulos à criatividade e compartilhamento de informações entre os funcionários fazem com que a empresa esteja sempre atual no mercado. A presente pesquisa visa analisar o processo de gestão de conhecimento em startups catarinenses, bem como definir os conhecimentos críticos referentes a esse processo.

Nesse mérito pode-se entender a abordagem de como é tratado o conhecimento dentro das startups analisadas, onde alguns pontos tem-se como conhecimento crítico. Simplificando o conceito de conhecimento crítico para nossa análise, ele seria o conhecimento que a empresa tem como relevante para seu funcionamento, outros pontos podem ser conhecidos pela empresa e até implantados inicialmente, mas não são extremamente necessários para seu funcionamento.

Para esta pesquisa, foi considerado conhecimento crítico aqueles assinalados com concordo e concordo muito. Os conhecimentos assinalados com discordo, discordo muito e neutro não foram considerados críticos. 
A maioria dos gestores assinalou neutro, discordar ou discordar muito para a existência de sistemas dentro da empresa para capturar o compartilhamento de ideias e experiências, e para facilitar o controle do conhecimento já disponível na organização, tornando a existência desses sistemas um conhecimento não crítico para as startups participantes da pesquisa. Os gestores apontaram que não existe um modelo de compartilhamento do conhecimento entre os envolvidos na empresa.

Outros pontos que não tiveram tanta relevância para os gestores entrevistados foram a existência de proteção para conhecimentos específicos, a necessidade de responsáveis para a conservação e manutenção do conhecimento e da criação de formas de apoio a criação de novos conhecimentos. Esses pontos foram apontados por Sveiby (1998) como necessários para a manutenção e crescimento de uma empresa no mercado, mas não são tidos pelas startups em questão como conhecimentos críticos.

Os demais pontos de discordâncias entre a teoria, como a de Alcará et al. (2009) por exemplo, e as respostas dos gestores seria em relação a motivação que a gestão da para que se compartilhe conhecimento através de confiança dando incentivos e recursos para que isso aconteça. A confiança possibilidade a integração entre os colaboradores é um fator primordial para que o conhecimento aconteça de forma eficaz e satisfatória segundo o autor.

Com os resultados obtidos na pesquisa, conclui-se as respostas de alguns pontos abordados no questionário demonstravam contradição entre os gestores e a teoria de alguns autores utilizados como base para a execução do trabalho. Portanto, ao contrário do que diz a teoria, em alguns casos, alguns fatores estudados não são considerados importantes pelas startups estudadas para o processo de gestão do conhecimento das empresas. Ou seja, mesmo estes fatores não sendo considerados garantia de crescimento por parte dos alguns gestores entrevistados, segundo a teoria essas características levam a uma possibilidade maior de que a empresa se mantenha forte no setor em que atua e com possibilidade de progresso da organização.

\section{REFERÊNCIAS}

BLANK, S. The for steps to the epiphany: successful strategies for products that wit. 2. ed. Cafepress, 2006.

CORMICAN, K.; O'SULLIVAN, D. Idea management for organisational Innovation. International Journal of Innovation Management. 2003.

DIHL, W. A Teoria da criação do conhecimento organizacional relacionada à elaboração de relatórios de sustentabilidade empresarial: um estudo exploratório em uma empresa geradora de energia. 2013. 119 f. Dissertação (Mestrado) - Programa de Pós-Graduação em Engenharia de Produção, Universidade Tecnológica Federal do Paraná, Ponta Grossa, 2013. Disponível em:

<http://www.pg.utfpr.edu.br/dirppg/ppgep/dissertacoes/arquivos/223/Dissertacao.pdf > . Acesso em: 07 dez. 2016.

EUROPEAN COMMITE FOR STANDARDIZATION. European Guide to good Practice in

Knowledge Management. Brussels, 2004.

ERMINE, J-L. Introduction au knowledge management. 2007. Disponível em:

$<$ https://www.researchgate.net/profile/JeanLouis Ermine/publication/228007736 Introductio $\mathrm{n}$ to Knowledge Management/links/02e7e53ac6a9ea3b74000000.pdf $>$. Acesso em: $20 \mathrm{dez}$.

2016. 
ERMINE, J-L. Valoriser les connaissances les connaissances critiques dune entreprise. Gestion dynamique des connaissances industrielles. Hermes Science publications: Lavoisier, 2004.

MIGUEZ, Viviane Brandão. Uma Abordagem de geração de ideias para o processo de inovação. 2012. 124 f. Dissertação (Mestrado) - Programa de Pós-Graduação em Engenharia e Gestão do Conhecimento, Universidade Federal de Santa Catarina, Florianópolis, 2012.

Disponível em: $<$ https://repositorio.ufsc.br/xmlui/handle/123456789/100942>. Acesso em: 07 dez. 2016.

MUNIZ, Suely. Investimento recente, capacitação tecnológica e competitividade. São Paulo em Perspectiva, São Paulo, v. 14, n. 3, p. 98-107, 2000. Disponível em: $<$ http://produtos.seade.gov.br/produtos/spp/v14n03/v14n03 14.pdf > Acesso em: 19 out. 2016.

NONAKA, I.; TAKEUCHI, H. Criação de conhecimento na empresa: como as empresas japonesas geram a dinâmica da inovação. 2. ed. Rio de Janeiro: Campus, 1997.

OCDE. Manual de Oslo: diretrizes para a coleta e interpretação de dados sobre inovação tecnológica. 3. ed. FINEP, 2006.

PEREZ-FREIJE, J.; ENKEL, E. Creative tension in the innovation process: how to support the right capabilities. European Management Journal, v. 15, n. 1, p. 11-24, 2007. Disponível em: <http://dx.doi.org/10.1016/j.emj.2006.11.005>. Acesso em: 13 jan. 2017.

RUS, I.; LINDVALL, M.; SINHA, S. S. A State of the Art Report: knowledge management in software engineering. Fraunhofer Center for Experimental Software Engineering Maryland and The University of Maryland, 2001.

SILVA, F. A. DE M. Fatores que contribuem para o insucesso das Startups: 0 reverso da "medalha". Portugual: Universidade do Minho, 2013. 